\title{
Epilogue: The Rise of Imagery in the Age of Modeling
}

Sabine Ammon

This epilogue examines the relevance of imagery in modeling processes in architecture, design, and engineering. In addition to the description of the current state of research, it includes the changes brought about by the use of computers and outlines the different forms and functions of design models to discuss the role of operative imagery in this context. A look at the contributions in this volume reveals that computer-based modeling is not repressing image-based practices. Rather, they are complemented by new forms, which overall strengthen their significance. Thus forms of imagery are crucial reflection tools at the operative level and with their help, design projects in architecture, engineering and design are developed, particularly also in the age of modeling.

The digital turn in designing seems to be characterized by a paradox: the success of modeling is simultaneously the success of imagery. The extensive use of computer-based models has not lessened the importance of image-based practices. On the contrary, as the examples in this volume make clear, new forms of image use are added to architecture, design, and engineering, without older forms losing their importance. Modeling processes are not only embedded in imagery phenomena, but they depend on the implementation of the latter. This intimate integration may seem strange at first glance, given that the relation between model and image is often characterized as a strong opposition. Predictability, precision, and scientific criteria are seen in opposition to intuition, vagueness, and design demands. This impression changes rapidly when imagery and modeling are examined from the perspective of their use. Then design artifacts and the processes and practices related to them come into focus. Precisely the perspective of operativity, described in this book's essays, is what opens a new set of questions that go beyond the established dichotomy. The fascinating richness of different forms of images and the enormous range of image functions comes to the fore, and their relevance in design processes cannot be better made clear. This epilogue considerations examine the relationship between imagery and modeling in design considering the current state of research in order to more accurately determine the growing significance of images.

A shift in meaning and its consequences. Supposedly, through computation the traditional relationship between imagery and modeling is turned upside down. Since the Renaissance, drawing methods have allowed the carrying out of precise and complex design tasks on a sheet of paper using pen, ruler, and compass. ${ }^{1}$ The emergence of the professions, in combination with the creation

\footnotetext{
${ }^{1}$ Maya Hambly (1988), gives an overview of historical drawing instruments.
} 
of more articulated representation systems and new forms of mass media communication, abetted this development. ${ }^{2}$ The design process was increasingly separated from the production process, as the case of architecture shows. For the first time, the conceptual architect emerged to replace the master builder trained in the actual practice. The former's defining medium was drawing.

Programmatically, this new self-understanding is reflected in the influential writings of architectural historian Leon Battista Alberti. “[T]he whole Art of Building," as he says in his 1435-6 treatise De re aedificatoria, "consists in the Design, and in the Structure. ... Which being granted, we shall call the Design a firm and graceful pre-ordering of the Lines and Angles, conceived in the Mind" (Alberti 1755: 25). Design work is presented here as a drawing task in plans and elevations in order to separate them based on a division of labor before the implementation in the construction site. In this context, models played only a subordinate role. They were mainly used to explain designs to the public and clients. Especially when geometric or statically demanding design tasks were present, models were introduced to the design development to support the drawn search for a solution. ${ }^{3}$ Although projection procedures and modeling techniques would be subject to further changes, the separation of tasks between model and drawing process remained essentially the same for several centuries.

With the increasing computerization a fundamental shift is introduced. The first generation software from the 1970s, which was referred to as computer-aided drafting, still tried to translate the classic drawing techniques into the digital age. ${ }^{4}$ Instead of using pen, paper, and compass, the work was carried out with keyboard, mouse, tablet, and screen. The basic drawing operations remained the same: simple geometric shapes in two dimensions, which resorted to elements such as lines, arches, and rectangles that were processed in a plane. With the second generation of software products in the 1980s, the change towards computer-aided design (CAD) took place. The programs were precisely tailored for user groups in architecture, aerospace or mechanical engineering in order to take into account their specific requirements. They also offered the first opportunity to work with basic 3D elements, such as cuboids, cones, spheres, or cylinders on the screen.

But it was especially the third generation computer tools, those that emerged in the 1990s, that have effectively transformed the relationship between imagery and modeling. With them begins the object-oriented 3D modeling, where product development takes place directly in the tridimensional

\footnotetext{
${ }^{2}$ For the history of the profession see the contributions in Ralph Johannes (Ed. 2009), and Alfred Nerdinger (Ed. 2013); for the impact novel communication media and mass media in the context of printing see Mario Carpo (2001).

${ }^{3}$ Well-known examples are the wooden models by Balthasar Neumann, the hanging models by Antoni Gaudí, and the models made out of soap bubbles by Frei Otto.

${ }^{4}$ The time-frames provided are just a rough orientation, as prevalent use was neither regionally nor disciplinary homogeneous. Early conceptual developments took place much earlier; comp. Bernhard Langer (2011), and Jon Peddie (2013).
} 
Cartesian system of coordinates by using domain-specific informational elements. These new tools not only modify the primary working techniques, which change from parallel projection to axonometry and particularly to perspective (as angle and length accuracy are now ensured by computational operations), but they also allow for a wide range of modeling procedures. These range from operations with multiple curved surfaces, parametric programming, and information modeling, to the automated production interface of computer-aided manufacturing (CAM). The model becomes the decisive factor in the design process, while, according to the vision of many, drawings and plans will only exist (if at all) as a niche.

Imagery's loss of importance can be clearly found in recent writings in architectural theory, where digitalization is celebrated as modeling. As "digital architecture," it captures the majority of the attention (comp. Spiller 2008). This position is paradigmatically represented by The Digital Turn in Architecture 1992-2012, a volume edited by Mario Carpo that discusses two decades of texts from the journal Architectural Design, one of the most important publications in architectural theory (Carpo (Ed.) 2013). Under imaginative labels like 'folding,' 'versioning,' 'scripting,' 'parametricism,' 'morphogenesis,' 'hypersurfaces,' or 'topological architecture,' the consequences of digital modeling tools as form-generators are explored. For Carpo, these new possibilities constitute "the reversal of the Albertian paradigm," as he states in Alphabet and Algorithm (Carpo 2011: 44). According to Carpo, the pairing of CAD and CAM brought to the increased concurrence of the design and implementation processes through digitalization. The blueprint, once sent to the factory and the construction site to describe through differentiated notations the designed object in an exact drawing, increasingly loses its relevance. Modern computer technologies will become, after Carpo, "a curiously high-tech analog of preindustrial artisanal practices" of the traditional crafts, which will cancel the separation between design process and realization introduced by Alberti (ibid: 45). In this theoretical context, it is not surprising that attempts to draw attention to visual phenomena such as the Bauhaus Colloquium 2007 The Reality of the Imaginary. Architecture and the Digital Image were not very effective (Gleiter et al. (Eds.) 2008). In the center of the current dispute is modeling, which irrecoverably replaces outmoded forms of design development. But is there really a displacement process taking place? Is modeling really ousting image-based processes? It is undeniable that with the introduction of computerization working processes have substantially changed. Much of what was traditionally solved graphically is currently the purview modeling processes, but can the increased importance of modeling be equated with a decreased importance of imagery? At the level of practice, the situation is not as clear. The computer-based model is largely developed with the help of drafting projection processes on the screen; stages of the model are printed out and are revised in the form of plans on paper. New image-based processes 
such as rendering, animation, or virtual tours are introduced to make possible other forms of development and revision. From this perspective then, the relation between imagery and modeling is significantly more complex: it is reason enough to examine the relationship in more detail.

On the concept of model in general and design models in particular. A significant difficulty when approaching this issue lies in the across-the-board and ubiquitous use of the semantic field of model and modeling. Around fifty years ago, Nelson Goodman realized with disillusion that only few expressions were used in a more undifferentiated way in both popular and academic discourse (1968: 171). Could have he anticipated that the concept of model in the course of computerization still had to undertake its actual career, his conviction that the use of the concept could be reduced to a few categories would have probably been less optimistic. What puts together classic works from the literature on models with recent characterizations and the description in the dictionary is the concept's dazzling complexity: sample, example, design, mock-up, form, one-off production, type, prototype, simplified representation, mannequin or even prostitute are only some of the terms in the German Duden dictionary (2005: 669). The impression of an ambiguity hard to restrain remains also when the question of what a model is is limited to the sciences. In his influential text, "Models and Archetypes," Max Black (1962) refers to scale, analog, mathematical, and theoretical models; in Allgemeine Modelltheorie, Herbert Stachowiak (1973) accounts for graphic, technical and semantic models; while in their survey article "Models in Science," Roman Frigg and Stephan Hartmann (2012) distinguish among physical and fictional objects, set theoretical structures, description, equations and also composite ontologies. This superficial recollection already insinuates a vast amount of ambiguities in the classification. It begins with conflicting ways of categorization that must determine whether models have to be differentiated according to their essence, function, object or perhaps their origin, and it ends with internal delimitation problems which are exacerbated by the fact that much of what is called a model could also aptly be designated in another way and with the fact that much of what could be appropriately named model, is called something else. ${ }^{5}$

In the philosophy of science, this oversupply of categorization proposals and uses of the term is opposed to an odd neglect of the specific characteristics of models in architecture, design, and engineering. This is all the more astonishing as the origin and history of the concept of model are closely related to these areas. Etymologically, 'model,' which has Indo-Germanic roots that mean 'measure,' goes back to the Latin 'modus.' The latter is not only reflected in the term 'mode' (way,

${ }^{5}$ The latter difficulty highlights Roland Müller (2009: 638). 
procedure, process), but also in derivatives from two sorts of diminutives, which are relevant for the current use. The English term 'mould,' which derives from the diminutive form 'modulus' in Latin, is limited nowadays to the technical language of the crafts and it refers there to the hollow forms in the casting process. The concept of model, in its turn, which emerged from the diminutive in vulgar Latin 'modellus,' in Italian modello, was formed around 1600 as a technical term in the field of fine arts and architecture and became the foundation for the actual concept of model (ibid: 638-642). Significantly, its development is now closely linked to the design process. In a lexicographical study, Roland Müller proves that the early contexts of uses referred to more than an intermediate stage in the creation of a sculpture in which the templates in clay or wax were formed and then realized in more valuable materials and materials more difficult to shape such as wood, terracotta, marble, or bronze (Müller 1983: 24ff). At least since the works by Alberti on architectural theory, the term designated also small-scale architectonic or engineering artifacts to develop or represent a design. An impressive example from this period is the Dome of Florence's cathedral. In order to obtain the contract, it was not enough to make a presentation model to convince the patrons. Filippo Brunelleschi, in order to be able to actually build the dome, needed a series of models to explore both the structure and the construction process with its cranes and lifts (see Müller 2009: 639). According to Müller, it is this "nuance in the meaning as a small-scale replica, or as a free playful design [... what] has paved the way of the concept of model as a technical term in the sciences" (Müller 1983: 46). Through some intermediate steps, an increasingly abstract use finally brought to the dissemination of the concept in the sciences until the current thriving that is replacing the concept's origins. But this historical reassurance allows precisely a new assessment of the role of models in architecture, design, and engineering. Not without reason can one find precisely in Müller a division of models as "models of the world" and "models as step in design" (Müller 2009: $642 \mathrm{ff.}$ $646 \mathrm{ff}$.). In addition to models used to represent the world, there are those that constitute an important part of the design process. With design models, Müller draws attention to a type of model which has gone virtually unnoticed by the literature on models despite its historical relevance and its solid significance in practice. Without being limited to the design disciplines, design models play a crucial function in these areas. With the help of design models, the still inexistent is unfolded in a step-by-step process; they allow in many iterative loops the exploration as well as the development of future artifacts. In the field of the designing disciplines, there are also depicting models; however, they do not play a significant role. They were granted significance especially in the $18^{\text {th }}$ and $19^{\text {th }}$ 
centuries teaching collections. ${ }^{6}$ Teaching in architecture and engineering took place through representations of existing artifacts to support the education of designing through examples, a task that nowadays has been especially taken over by visual templates. ${ }^{7}$

Borrowings from the philosophy of science. The special position of design models can hardly be better illustrated than with the distinction between models of and models for. Most of the literature in the philosophy of science deals with the question of in what way models succeed in making valid statements on a target system, i.e., in being a model of something (Frigg \& Hartmann 2012). As a preferred area of study, physics prompts not only to put in the center questions of representation and semantics, but also to mainly understand this representational relationship under its logical and mathematical conditions, precisely because physics is accessible to a large extent through mathematization and axiomatization. For a general model theory, there is a great danger that specifics of the area of study be declared generic of the model character. As a consequence, not only special forms - such as that of the design models - fall through the cracks of the investigation, but they cannot be described in a meaningful way within the context of the prevailing theories. Thus it should not be surprising that important urges to overcome this narrow understanding of models come from research in other areas of study. And these in turn can help to better understand forms of modeling in architecture, design, and engineering. That the predominant discussion falls short became clear thanks to Evelyn Fox Keller's essay "Models of and Models for: Theory and Practice in Contemporary Biology." 8 This philosopher of science demonstrated, through the example of the regulation of gene activity, that often, in models, there are two functions intertwined. On the one hand, they can be 'models of' something that represent a particular theory or empirical phenomena, but on the other hand they can also be 'models for' something that are linked to actions and practices in order to pursue certain objectives. In her example, Fox Keller shows that it is not enough to ask how models can represent theories, but that it should also be investigated for what they are used. This is even truer for the technical field. For here the issue is

\footnotetext{
${ }^{6}$ An overview of teaching models can be found in the database of objects of university collections in Germany ("Universitätssammlungen in Deutschland"), http://www.universitaetssammlungen.de/modelle (Accessed 28 Aug 2015); see also Stefanie Bräuer (2015) as well as Oliver Zauzig (2015).

Other forms of depicting models are 'control models' used for conversion or as exhibition models in the context of the museum: see Hans Reuther and Ekhart Berckenhagen (1994: 12); a historical curiosity are the cork models of the ruins of Rome: see Werner Helmberger and Valentin Kockel (Eds. 1993).

${ }^{7}$ Especially catalogues raisonnés or (architectural) journals convey photographic archetypes; for the genre of architectural journals see Eva Maria Froschauer (2011); for the genre of architectural photographs in the same book: Rolf Sachsse (2011). One should also mention reconstruction models, as they are discussed by Sander Münster, Peter Heinrich Jahn and Markus Wacker (2016). As the authors show, precisely in the speculative assumptions is a smooth transition to design models to be found.

${ }^{8}$ Evelyn Fox Keller (2000). A similar argumentation can be found in Bernd Mahr (2008). He identifies models of and models for both as "the fundamental relations of models" (ibid: 216).
} 
not primarily about descriptive questions on the representation of the world or phenomena, but rather the implementation of normative objectives is the main priority. According to Christoph Hubig, in the technical application, the latter is, precisely, the determining factor, i.e., the "models of' become 'models for' during the technification (2010: 217f.).

Design models need to be conceived even more radically, inasmuch as they could be considered as a special form of technical models. Since when visions and scenarios are created, showing how the world might be, when the world is not unveiled but rather being made, models (strictly) do not represent anything. ${ }^{9}$ During the actual handling, there is no object of reference, because it is precisely the model's job to create something that does not yet exist. Therefore, they are not models of something, but models for something. Used to support the design process, new artifacts should be developed with their help. This requires reliable knowledge on the future object; in the genesis of these insights, design models play an important role as instruments of cognition. This is not, however, knowledge about the world as it is, but about the world as it could be. The epistemic capacity of design models can therefore be explained not through representation or depiction, but other conditions, such as calibration, verification and validation by research instruments, tools, and techniques, are the ones that apply. They are not built to comply with theories or to draw conclusions about a phenomenon or a target system, and thus its cognitive potential needs to be justified by its intrinsic operativity alone.

An important contribution to the issue of learning with models is Models as Mediators. Perspectives on Natural and Social Science, an anthology published in 1999 by Mary S. Morgan and Margaret Morrison and whose findings are partly transferrable to the design situation. Their approach is also directed against the prevailing semantic approaches, according to which models play a central role in the genesis of knowledge and our explanations of the world, however at the cost of being completely dependent on a theory. And it is precisely this, according to Morrison and Morgan, which makes semantic approaches implausible since they cannot explain why models become "instruments of investigation," they cannot explain why we gain knowledge through its construction and manipulation. Instead, they propose to conceive models as "autonomous agents" (Morrison \& Morgan 1999: 10). How models can start up learning processes from their autonomy is illustrated by Morgan with the example of the development of quantity theory of money in economics at the beginning of the 20th century. In her article "Learning from Models," Morgan traces the attempts of American economist Irving Fisher to determine money's purchasing power

\footnotetext{
${ }^{9}$ The concept of representation can easily be misleading, as it suggests a relation of depiction which is not necessarily given. Hence, representation in the narrow sense means a relation of depiction, representation in the broad sense also embraces also other (non depictive) forms of reference.
} 
and thus its value. From here, she extracts two ways in which we learn from models: by building them and by working with them. Learning from building "involves finding out what will fit together and work to represent certain aspects of the theory or the world or both" (Morgan 1999: 386). This requires making certain choices, and this requirement entails an important learning effect. The internal structures, which are partly explicitly chosen with a rational intention, constitute in turn the starting point of further learning processes (ibid: 352). Learning from using, on the other hand, "is dependent on the extent to which we can transfer the things we learn from manipulating our models to either our theory or the real world" (ibid). According to Morgan, however, this does not happen in any designated or necessarily linear way. Rather, in the application one should find out what properties can be significant and in what respect; to learn these properties means, at the same time, to learn about the limits of the model and its failures in certain respects.

Morgan's distinction between learning by building and application of models should not occur separated from one another, especially in the design process, but be directly connected in practice. This important observation is directly linked to an effect that Marcel Bouman refers to as "built-in justification" in an essay with the same title and that also applies to designing (1999). By analyzing three sorts of economic models he demonstrates that modeling happens in an extremely complex combination of different components and where the justification of the model takes place simultaneously. Discovery and justification go hand in hand: by building the model, the consolidation of the insights is already happening. The combination of components takes place in case studies through "mathematical moulding" (Boumans 1999: 90f.), which fuses together very heterogeneous components: "theoretical notions, metaphors, analogies, mathematical concepts and techniques, policy views, stylized facts and empirical data" (ibid: 94f.). As Bouman emphasizes, there is not one necessary way to combine them. Rather, he wants to understand the process as a sort of baking without recipe, which is satisfactory when a series of criteria a priori are met; these are, however, too specific to be applied to the design area given Bouman's definition. Nevertheless, the design process faces similar challenges as the described economic theory construction. A variety of extremely different categorical components have to be brought together in modeling, such as: space allocation plan and local particularities, static, physical, economic, safety, legal or political and cultural requirements, aesthetic ideals and concepts. And this without a pre-established 'recipe' or pre-fixed components, given the diffused starting conditions.

Consequently, Mieke Boon and Tarja Knuuttila talk about models as "epistemic tools" (2009: 695). Their essay "Models as epistemic tools in engineering sciences" is one of the few investigations that deals directly with the use of models in engineering. Through the example of Carnot's heat engine they show how models in engineering can serve to create and optimize specific machines or 
materials. The epistemic value of these models is anchored in practice: according to Boon and Knuuttila, the production and manipulation allow drawing conclusions about and justifying the thermodynamic cycle and the maximum efficiency of an ideal heat engine. The definition of modelbased reasoning by Nancy Nersessian and Christopher Patton is representative of this finding. According to Nersessian and Patton, "an instance of model-based reasoning: 1) involves the construction or retrieval of a model, 2) derives inferences through manipulation of the model" (2009: 751). ${ }^{10}$ In connection, they mention a third criterion, i.e., that " 3 ) those inferences can be specific or generic, that is, they can either apply to the particular model or the model [can be] understood as a model-type, representing members of a class of phenomena." It is symptomatic of design models that they deal with particular cases, i.e., that they generally develop specific and targeted conclusions. Generic conclusions that definitely arise in design processes are almost never made explicit. They are mainly stored as disperse design knowledge in the designers' treasure trove of experience.

This very fact shows once more why it is important to consider design models separately. Then, by far, not every model in engineering is a design model; significant differences are illustrated by William Froude's experiments on the effects of scaling, which Sjoerd Zwart discusses in his article "Scale Modeling in Engineering. Froude's Case" (2009). ${ }^{11}$ One of the challenges for the development of artifacts is that their flow properties change with the same geometric proportions but increased size. This happens especially in boats and planes, but it can also play an important role in very large buildings. Looking at smaller model ships, such as Raven, Swan or H.M.S. Greyhound, Froude sought to find a law to predict water resistance and stability of actual full-sized boats. The scale models here are not design models, but they are part of an experimental environment in order to gain reliable forecasts about scaling properties of model ships. The correlations found, such as the Froude number as a dimensionless parameter, can in turn be used to analyze design models. When a particular ship is designed, a smaller model can be tested in the water channel or in a simulation process. The generic rules from the experimental context can then be transferred to the individual case to derive specific statements about the design.

To end with the overview, note that a striking feature of all the presented case studies is that in learning processes based on models there is not only one model used but rather different models that are deliberately resorted to and which are interwoven when used. In Morgan's investigation,

\footnotetext{
${ }^{10}$ Nersessian and Patton base their thoughts on a very broad concept of model; they understand model as "a representation of a system with interactive parts with representations of those interactions" (ibid). Model-based reasoning was introduced as an important keyword in the discussion by Lorenzo Magnani, Nancy Nersessian and Paul Thagard (comp. Magnani, Nersessian, Thagard (Eds.) 1999; Magnani, \& Nersessian (Eds.) 2002).

${ }^{11}$ Ship models are also discussed in Simon Schaffer (2004).
} 
Fisher used three models for his theory, an arithmetic one, a mechanical one and an algebraic one. He could work out specific aspects in each model and approach the issue from different perspectives. Precisely because models can only provide knowledge in certain points, it is important to use different models in parallel. Nersessian and Patton point to the fact that, in the model construction, on the one hand, domain limitations of the target problem are addressed, but on the other, those limitations in the source (and therefore of the model's working materials) are incorporated. The limitations could be of a completely different nature: spatial, temporal, topological, causal, material, categorical, logical, or mathematical. In addition, in the manipulation of the model, which Nersessian and Patton term "simulation," new limitations could appear, or other limitations previously overlooked could come to light (2009: 751). Many of Nersessian and Patton's described observations from the field of synthetic biology also apply for the design context. In both simulation and design processes, one cannot directly work on the object, be it because it is too vague, too complex, too inflexible, too big, too prolonged, too costly, or too dangerous. The work has to be done with proxies. Since models can always only provide statements about specific aspects on that which they explore, one has to find out which aspects of the problem can be examined with their help and where are the corresponding epistemic limits. At the same time, the modeling material already brings with it certain conditions that are deposited in the exploration; its selection is thus of great importance in order to be able to use it for the targeted knowledge purposes. This also explains why models are often paired. In this way, one can not only examine different aspects of the problem that complement each other when dealing with partial questions, but rather it allows contrasting and, by this, uncovering conditions of the source materials and balancing them out; this is a key requirement to avoid distorting the results. This also makes clear why, as Boon and Knuuttila emphasize, "the importance of different representational means for model-based reasoning" (2009: 723) cannot be underestimated.

Provisional Attempt of a Typology of Design Models. Whoever tries to describe design models more accurately is confronted with a confusing variety of models. Already within a single design process one has to resort to different models. Depending on the design phase and the problems, it may be necessary to resort to other development contexts. How this is taken to the extreme in an artistically motivated project from the late 1990s is described by Nathalie Bredella in "Visualization Techniques and Computational Design Strategies: Reflecting on the Milieu and Agency of Digital Tools in 1990s Architecture" (this volume). The different stages of the design process require other software and thus also the development of new models. Even though software development has been since then consolidated and a series of applications are currently offered 
within a framework model, the problem persists in the core. As with classical tools to design on paper, each software is a specialized tool that is used for specific tasks in the design. But since programs use proprietary data formats, only part of the information can usually be transmitted through the interfaces, and as a consequence, a strong reworking of the modeling is necessary due to the follow-up software. Beyond that, in the course of a design process there is a collision of different groups of experts working with domain-specific software and other modeling procedures. In interdisciplinary design discussions not only different perspectives clash, but there are different underlying modeling procedures that need to be coordinated and agreed upon. Another challenge lies in the nature of the artifact to be developed: specific demands on the modeling depend on the final product. Depending on whether it is a one-off production with manual and artisanal intermediate steps (as in the building industry) or a mass product that is ready to be produced through various stages of prototypes (as in product design), different forms of models are necessary. Thus the following brief overview must necessarily remain cursory. It partly focuses on architecture, although many of the distinctions are likely to apply also to engineering and design due to their disciplinary overlap. ${ }^{12}$ Based on their primary functions, design models can be divided into three groups. Development models, i.e., design models in the strict sense, serve primarily to explore and develop the design. Analysis models support this by examining in depth selected design variations under specific laws. Finally, production models serve to convert the design into actual artifacts in a mechanical and partly automated way. This division, however, is mainly based on an heuristic motivation in order to clarify some of the strengths and focal points of modeling. In practice, there are smooth transitions, which are even more conflated due to software development. Where a few years ago new model creations were still necessary, high-capacity programs can integrate different functions nowadays.

The archetypal development model is the traditional model made out of wood, cork, paper, cardboard or plastic. It is often referred to as scale model, since it examines the design object in a fixed, reduced scale. ${ }^{13}$ When used in early design phases, it enables intuitive handling. Features of the model's materials can be specifically used to investigate certain aspects of the design in more detail. ${ }^{14}$ A key challenge for the model is thus to find suitable materials for each issue in order to

\footnotetext{
${ }^{12}$ An outline for architecture can be found in Philipp Geyer (2013: 235-244).

${ }^{13}$ A difficulty for the documentation of designerly working models is that they usually are disposed after using them (in contrast to presentation or teaching models in archives or publications; this is why the latter determine - and distort the image of skale models); see Oliver Elser, Peter Cachola Schmal (Eds. 2012); see also fn. 6. A discussion of scale models in theory of architecture can be found in Albert C. Smith (2004), connected with the claim to investigate them as "thinking mechanisms" (ibid: xvi ff.); for the makers perspective see Mark Morris (2006).

${ }^{14}$ Architect Günter Behnisch points out the subtle influence of materials for shaping: "Every planning stage has its materials and techniques. [...] Card-like, plane, immaterial houses originate in cardboard models, chunks of wood turn
} 
use them in a targeted manner. Depending on which aspects are in the foreground, be it its geometric expansion, its structural behavior, the illumination situation or the atmosphere, the model can convey valuable insights regarding certain aspects, but regarding others, it can point to wrong ones. For example, a model to study structural behavior often loses explanatory power regarding form, since the effects of scale involve other dimensions. For its use, it is thus crucial to know in which respect each model can provide reliable information. This type of exploratory 'working models' should not be confused with the so-called 'presentation models.' The latter usually do not contribute to the design development, but they are rather realized on the basis of a stabilized planning stage to show a certain (intermediate) result to clients, the public or a jury. Regarding their representational conventions and their meticulous design, these models often differ significantly from design models. Their particular function is also reflected in the preparation and realization processes. However, the significance of the archetypical scale models diminishes in the context of digitalization. Still, the significantly slower and more time-consuming computational modeling occurs momentarily in the advanced design phases. There, where flexibility, speed, and many variations are required, sketches are predominant, as Gabriela Goldschmidt's essay "Manual Sketching: Why is it still relevant?" (this volume) shows. That this doesn't necessarily mean the traditional hand-drawn sketch, but that in the future, digital techniques could also make possible a gestural sketch, is illustrated by Irene Mittelberg, Thomas H. Schmitz, and Hannah Groninger in "Operative Manufacts: Gestures as immediate sketches in the early stages of the design process" (this volume). But precisely the digitalization detour indicates a renaissance of the scale model that will be discussed later.

Geometric modeling is currently prevalent among computer-based development models. A distinction is usually made between computer-aided $2 \mathrm{D}$ and $2 \frac{1}{2} \mathrm{D}$ drafting methods and the actual 3D modeling, which in practice are often used in combination. Underlying 2D planning are models limited to two-dimension projections (be it the xy-planes for floor plans or the xz- and yz-planes for elevations and sections); in $2 \frac{1}{2} \mathrm{D}$ planning, the two-dimensional geometric elements are assigned an offset value, which attributes height. A wall, for example, is conceived as two adjacent lines corresponding to the projection procedures; consistency between floor plans, elevations, and sections must be ensured by the designers themselves. In 3D modeling, however, the geometric elements are registered through $\mathrm{x}, \mathrm{y}$, and $\mathrm{z}$ coordinates, and the wall becomes a square with width, depth, and height. This results not only in a significantly greater geometric design freedom, which allows the development of free-form surfaces curved multiple times, but rather plans, elevations,

into a chunk-of-wood-architecture, and plasticine evocates relatively free plastic buildings" (quoted after Gänshirt 2007: 155). As Christian Gänshirt correctly points out, there is no necessary connection. 
and sections can be derived directly as 2D projections; they are linked to each other through the model, whereby a significant source of error is eliminated and consistency of projections is guaranteed.

Parametric modeling is an extension of geometric modeling. Here, the operation chains necessary to produce geometric objects become part of the model. Through this, selected properties can be specifically addressed and changed, thus allowing also changing all dependent operations in accordance to the "construction logic" (Geyer 2013: 238). Returning to the example of the wall: in parametric modeling, the dimensions of the wall are shown as variable parameters; the same applies to the door opening, which is not described in absolute coordinates but in dependence of the wall. If the wall has to be moved at a later stage and its thickness reduced, the dimensions of the door opening are automatically modified. This modeling technique, already in use since the 1980s in mechanical engineering, has gained great notoriety over a decade later in architecture and design under the name of 'parametric design.' The possibilities of parametrical relations are used in particular for the genesis of forms, leading to new geometric constellations that cannot be achieved with conventional methods. By linking subordinated geometric objects and groups of objects with contextual conditions, dynamic adaptations can take place. The results are elaborately shaped, seemingly organic free-form surfaces, as they are exemplarily described in Rivka Oxman's essay “The Role of the Image in Digital Design: Processing the Image versus Imaging the Process" (this volume).

Another development is information modeling, which is not limited to the development process, but it also includes, explicitly, the production and utilization processes. Information modeling has undergone different disciplinary variations; in architecture it is named building information modeling (BIM), in product development it is known as product data or product lifecycle management (PDM/PLM). Its aim is twofold. On the one hand, the goal is to expand parametric and geometric modeling with additional information through standardized object definitions.

Continuing with the example of the wall: the wall is no longer a geometric cube, but it is directly considered as the architectural element wall, which is determined in more detail by a series of features. This allows CAD data to be expanded with further indications on the wall structure and its materials, the features of the connections, systemic dependences or succession within the planning and constructions process. As a consequence, material quantities for cost planning and contracting, or detailed instructions on the construction process, for example, can be directly derived from the model; at the same time, the changes in the wall are updated for all related objects, which avoids common planning mistakes. On the other hand, information modeling aims to bring together information inventories from scattered individual models and, collateral to the project, to coordinate 
and document it. ${ }^{15}$ Standardized object definitions can here serve as exchange formats to harmonize information flows from different models of the various disciplinary planning groups. ${ }^{16}$ Systematic recording and documentation can improve critical intersections in the lifecycle phases between planning, implementation, and use, which often lead to a loss of information and problems in information management. Daniel Cardoso's essay, “Architecture and the Structured Image: Software Simulations as Infrastructures for Building Production" (this volume), discusses examples of this sort of modeling.

Analytical models are a second set of design models. They are used to examine in depth a specific stage of the project considering certain questions. A known example is the already mentioned scale model of shipbuilding, the flow properties of which are tested as a specific design variant in the water channel. ${ }^{17}$ The findings obtained through the experiments are incorporated back to the further development of the design. Many analytical models are no longer created as material artifacts, but they are computerized. Johannes Lenhard's contribution, “License to Explore: How Images Work in Simulation Modeling" (this volume), discusses computational fluid dynamics (CFD); in "On Fuzziness and Relationships: Abstraction and Illustrative Visualization in Snow Avalanche Control Planning" (this volume), Doris Hallama discussed how avalanche simulations directly affect the design of open spaces in alpine valleys. In the computer-based application, it is still often the case that simulation software cannot resort to the development model, but a new model must be created. This is because of the lack of compatibility between data formats and also because of the different emphasis in the modeling process. Implementation is often in the hands of external groups of experts, which are selectively brought into the design development to clarify certain partial questions. Depending on the task, finite element modeling (FEM) can be used in the building industry to check static load, and building performance simulation (BPS) can be used to determine the building's energy performance; specific light and acoustic simulations are also employed. As Mehul Bhatt and Carl Schultz clearly show, novel analytical processes allow the integration of aspects insufficiently considered until now (such as visual orientation in space) to the search of design solutions (see "People-Centered Visuospatial Cognition: Next-generation Architectural Design Systems and their Role in Conception, Computing, and Communication," this volume).

\footnotetext{
${ }^{15}$ Different strategies for the implementation of BIM currently compete with each other, let it be through modeling a comprehensive global model, the conjunction of different individual models or the establishment of a shared project space. By connecting numerous stakeholders and companies difficult questions arise with regard to copyright and accountability.

${ }^{16}$ This is done with standardized interchange formats; IFC (Industry Foundation Classes) is established in the building industry, STEP (STandard for the Exchange of Product model data) in engineering.

${ }^{17}$ An interesting case study of an analytical model discusses Michael Weisberg (2013). The San Francisco Bay-Delta Model, a scale model, was built to investigate the consequences of potential new barriers in the bay. As a direct outcome of the investigation, the plans were given up.
} 
A third and final set of design models can be integrated under the heading of production models. A series of different techniques controlled through computer was developed to automatically implement designs, which are generally termed computer-aided manufacturing (CAM). In practice, a distinction is made among additive procedures (iteratively adding materials), subtractive procedures (removing materials), reshaping procedures (modifying raw parts) and joining procedures (permanently connecting several work pieces).$^{18}$ For this, CAD data must be prepared, i.e., converted into machine-controlled codes according to the production requirements; geometric data are translated by specific software for manufacturing instructions and on this basis activate, for example, the CNC-milling in an automated production. Rapid prototyping can feed an intermediate phase as a partial model or prototype back to the design process; if the artifact is produced directly for use in a 1:1 scale, there is a smooth transition to rapid manufacturing. Rapid processes are among the most additive production techniques; its particularity is that the work pieces are constructed in layers. For this, the complex 3D geometries of CAD models have to be translated into stacked 2D production layers. An area especially important for the construction of models is 3D printing, through which powdered materials such as silicon, ceramic, plastic or cement are glued together with adhesive. Thus at the end of this short survey, the circle is closed again at the initially described scale models, although now they are understood as physical-material derivatives of a computer model.

On the richness of visual artifacts in design processes. A striking feature of the omnipresence of computer-based models is that the operational level is dominated by forms of imagery. We find sketches and collages, which are important especially in early stages of design development, standardized notations in plans and static calculations, 3D visualizations in renderings and animation, function diagrams (as they appear in utilization schemes, project planning or materialflow analyses), or visualizations, which are necessary in more complex analyses of data sets to be able to use the results from energy, light, acoustic or flow simulations. But the screen interface already works mainly with graphical means, which are supplemented by numerical or verbal input. The geometric projection procedures of the development and production models meet here the diagrammatic procedures of analysis techniques. In practice, hybrid forms of work predominate (see Sabine Ammon's “Image-based Epistemic Strategies in Modeling: Designing Architecture after the Digital Turn," this volume). The digital processing on the screen with mouse, keyboard, or graphic tablet is followed by the printout on paper, which is further developed with handwritten notes and

\footnotetext{
${ }^{18}$ For an overview see Moritz Hauschild, and Rüdiger Karzel (2010: 44-69).
} 
sketches during an exploration phase and then transferred again to the work on the screen. In this dynamic development process, retaining a particular state plays an important role: as a print-out of a plan, renderings or analytical diagrams, results can be documented or fed into new revision rounds. In her contribution, “Architectural Drawings as Symbols: A Goodmanian Account of Epistemic Practices in the Design Process" (this volume), Remei Capdevila-Werning discusses how the same sort of image can adopt differing tasks depending on the context and how different sort of images cooperate in a comprehensive design task. Of major importance are hence the governing projective systems, which historically show a non-linear change, as Reinhold Martin argues in "Points of Departure: Notes Toward a Reversible History of Architectural Visualization" (this volume).

The richness of different kinds of images and the variety of tasks that they realize in design processes are, however, completely at odds with their omission by the research literature. Design images are insignificant in the comprehensive anthologies The Scientific Image by Harry Robin (1992), an inventory of scientific visual forms from the Stone Age to the present, and the investigation Images of Science by Brian J. Ford (1993), a comparative study. Even the volume The technical image: A history of styles in scientific imagery, edited by Horst Bredenkamp, Birgit Schneider and Vera Dünkel (2015), and which is to be understood as a compendium of scientific images in the broad sense, addresses images from the engineering sciences only marginally. The situation is better in Bild und Erkenntnis, edited by Andreas Beyer and Markus Lohoff (Eds. 2005), which presents a cross-section of current image production from natural, technical and life sciences; also Klaus Hentschel's comprehensive overview, Visual Cultures in Science and Technology (2014), includes images produced in engineering in the form of a comparative history of images. There is something to note, however, regarding most of the image-theoretical analyses of this type: what is shown are not actual design images, but what could be best described as technical illustrations. These are representation forms, made for presentation purposes and often found in publications for specialized or lay audiences. They are created or edited retrospectively after the design process is over and have usually undergone another creative transformation. Technical illustrations cannot be confused with the production of images in design, which serve as reflection and working tools.

In his monographic Drawing Distinctions, Patrick Maynard develops a philosophy of drawings and notes that " $[\mathrm{b}] \mathrm{y}$ far the most important modern kinds of images would be drawings, and not artistic ones but technical and design drawings" (Maynard 2005: 7). Unfortunately, the relevance of the latter is not reflected in the debates. In the philosophy of the image, it is repeated what was already observed in the discourse on models: apart from sparse exceptions, different kinds of images in 
design have gone almost unnoticed. This may also be related to the fact that they do not fit into the usual schemes of analysis. If image theory is more embedded in aesthetics and art history, then artistic forms of image are in the foreground; if, on the contrary, they are integrated in the philosophy and history of science, then the examples from natural sciences are in the center. Even in comprehensive image-theoretical approaches such as Klaus Sachs-Hombach's Bildwissenschaft (2005) or in James Elkins' Visual Studies (2003), this important area of images receives no attention. While design image forms share characteristics with other imaging phenomena, there are at the same time too many differences to plausibly include them in one of these areas. They share with scientific images the contribution to genesis and mediation of insights, but design images explore not what exists, but what does not exist. Precisely, the presentation of the non-existent is what design images have in common with fictional images, but they follow different standards of rightness, since the latter are not subject to the constrain of concretization due to their later transformation into actual artifacts. The capacity to act as image-based instructions is possible through a specific notational structure, which design images share in turn with many diagrams; in diagrams, however, the depicting function is in the foreground. It is not without reason, therefore, that in his essay "Bilder in Wissenschaften, Design und Technik," Oliver Scholz separates "design images" from "depictions" (Scholz 2012; comp. also Scholz 2009). He refers to the different intentional directions of both types of images, depictions having an image-to-world directedness, in which the image is adapted to the world, and design images with a world-to-image directedness, where the world is adapted to the image (Scholz 2012: 48). In the same way phenomena of "notational iconicity" 19 have been worked out by Sybille Krämer, design images display an epistemic operativity while being used. In this way, such images can become thinking tools that enable complex cognitive activities in their generative operativity and, on the other hand, their instrumental operativity is the requirement to enable the implementation of the design into actual artifacts. $^{20}$

The neglect found in image theory is opposed to a wealth of research in the history of architecture and of engineering. Countless volumes document visual artifacts from design processes according to different priorities, be it a documentary one when presenting collection items, a classificatory one when clarifying different epoch emphases or characteristics of specific forms of image, or an opusoriented one when emphasizing individual performance. ${ }^{21}$ When a systematic and epistemological

\footnotetext{
${ }^{19}$ With this concept Sybille Krämer encompasses scripts, maps, and diagrams (2009).

${ }^{20}$ For the distinction between generative and instrumental operativity using the example of façade design see my chapter in this volume; comp. also Sabine Ammon (2015).

${ }^{21}$ Given the abundance of material, it is only possible to refer exemplarily to Peter Jeffrey Booker (1963), and Antoine Picon (1992) (on engineering drawings), Winfried Nerdinger (Ed. 1986), Eve Blau, and Edward Kaufman (Eds. 1989), Annette Spiro, and David Ganzoni (Eds. 2013) (on architectural drawings).
} 
interest prevails, one can also gain important clues to narrow forms of design images from historical investigations. Eugene Ferguson, who in Engineering and the Mind's Eye describes designing and constructing as a cognitive process, wants to discover "the nature and significance of nonverbal thought in engineering" (1992: xi). Using the example of sketches, he clarifies the cognitive capacity of image-based ways of working. Depending on their task, he distinguishes the "thinking sketch," in which the individual reflection process is directly condensed, the "talking sketch," introduced as a communication tool in discussion contexts, and the "prescriptive sketch," providing concrete instructions. A similar assessment is also found in Ken Baynes and Francis Pugh, who in The Art of the Engineer (1981) discuss engineering drawing between 1750 and $1914 .^{22}$ They compare the notation process to a language, the help of which allows devising designs and that is introduced in addition to verbal specifications and descriptions. For Baynes and Pugh, the emerging variance in images is anything but accidental. "Variety is functional" (ibid: 14), they say. It responds to the different requirements in the design process in the field that spans from blurred search for ideas to exact instructions. The authors propose a typology for classifying engineering drawings, which begins with "designers' drawings." This corresponds to a phase in the design process in which the various alternatives have to be considered and a sketchy draft is created. The vagueness of the draft situation can be captured and addressed in this drawing process that leaves certain aspects deliberately open. "Project drawings," mostly at small scale, are able to provide a comprehensive overview in standardized notation processes. Generally, "production drawings" are compounded of a rich set of plans and handle the design from the overall arrangement up to many details. No longer part of the design process in the narrow sense are, on the one hand, "presentation and maintenance drawings," which usually survive in archives and were produced in a highly sumptuous and accomplished graphic way to document and present a finished (and executed) design; on the other hand, there are the already mentioned "technical illustrations." It is thus not surprising that an important instigator does not come from image theory, but from the discussion within the field itself, which allows to better understand the media-mediated operativity of design images. In his 1986 essay "Translations from Drawing to Building," architectural theorist Robin Evans argues for the recognition of the "power of drawing as medium" (Evans 1997: 154). To believe that a drawing could be translated into a building without bends, breaks or losses is for Evans a naïve assumption; precisely, in order to understand the particularities of drawings, it is crucial to look in greater detail what differs between drawing and later building. He refers to the "generative role" of architectural drawings that arises from the fact that architecture cannot directly

${ }^{22}$ Their emphasis is on naval architecture, vehicle construction, and aircraft construction in Great Britain. 
work on the object, a feature that clearly distinguishes it from painting and sculpture, but also - as it should be expanded beyond Evans - from crafts (ibid: 156). For Evans, the logic of classical realism is turned upside down: "Drawing in architecture is not done after nature, but prior to construction; it is not so much produced by reflection on the reality outside the drawing, as productive of a reality that will end up outside the drawing" (ibid: 165). In this difference that Scholz coins as "difference in directedness," lies for Evans the huge and until now hardly noted generative power of drawing, the projection procedure of which influences architectural shaping. As he shows through several examples in this posthumously published monograph, The Projective Cast. Architecture and its Three Geometries, the current projection procedures favor specific forms of architecture, the "underlying order" of which is characterized by frontality, symmetry, flatness, squareness and axiality (Evans 1995: 121). To sum up, Evans states: "Buildings, although not completely determined by its means of production [...] are enormously influenced by them" (ibid). ${ }^{23}$

There are also investigations from the field of science and technology studies, which typically pay more attention to imagery, that illustrate the epistemic potential of design images. In her extensive work, On Line and on Paper. Visual Representations, Visual Culture, and Computer Graphics in Design Engineering (1999), Kathryn Henderson traces the "mixed-use practices" between traditional drawing techniques with pen and paper and computer-based tools. Even if her participant observations stem from the early days of digitalization, much of her work retains its validity nowadays. Symptomatic is the case of a draftswoman who, promoted to engineer, was deprived of her drawing board. She asked to have it back on the grounds that only with it she could think properly. "In the drawing process is where the actual reflection takes place," the woman described in a subsequent interview (ibid: 82). What applies to the individual work is, for Henderson, also valid to the team-oriented design process. As "boundary objects" drawings can convey contents, assume different perspectives and circulate among various groups of experts. According to Henderson (ibid: $51 \mathrm{ff} ., 74 \mathrm{f}$.), these graphic products represent “conscription devices," inasmuch as they tie knowledge together and make it workable - a finding confirmed by the studies of Boris Ewenstein and Jennifer Whyte (2009) in the field of architecture. ${ }^{24}$

The psychologically-oriented design research examines these image-based reflection processes more accurately. In her essay “On Visual Design Thinking: The Vis Kids of Architecture,” Gabriela

\footnotetext{
${ }^{23}$ In connection to Evans, within theory of architecture the question of the relevance of forms of projecting has been raised by several people; comp. Alberto Pérez-Gómez, and Louise Pelletier (1997) who discuss the relevance of the perspective; Marco Frascari, Jonathan Hale, Bradley Starkey (Eds. 2007); Mario Carpo, and Frédérique Lemerle (Eds. 2008). Christopher Hight (2012) makes an effort to transfer Evans' argument to the conditions of digital design.

${ }^{24}$ A similar account regarding the usage of models is given by Albena Yaneva (2009).
} 
Goldschmidt (1994) illustrates how thought processes take place through sketching. She describes the example of a student who, dissatisfied with the previous development, initiates a new design approach through spontaneous and random scribbles. The sketch opens a "problem space," it gives 'clues' on how the design could be further pursued, and a reflection process that leads to further variations is initiated. Goldschmidt is not interested in an alleged recording processes of mental images (as the design idea is not available at that time). She rather wants to show how, through the sketching process, the design is developed in the first place. In this context, Donald Schön speaks of a dialogue with the materials of the situation, which 'talk back' and push the designers towards new thinking processes (1983: 78f). It seems thus consistent to speak about visual or visual-spatial forms of reasoning, as Barbara Tversky and others do (comp. Tversky 2005). Through many iterative loops, a solution can emerge on the basis of an image-based reflection process. Drawing processes become thus a crucial epistemic tool to develop and review the design.

Confusions and deviations. At this point, a cautious conclusion brings a confusing situation. From an epistemological perspective, the inventory of imagery sounds like an echo of the model character. In design context, techniques of image processing and modeling are important epistemic tools that help to explore that which still does not exist. The variety of forms has a functional character and supports the cognitive process. The epistemic gain lies in the handling: in practice, through specific reasoning forms, insights are gained, findings are confirmed, and knowledge is solidified. Should models, therefore, be treated as images, or images as models, or even equate images and models? Each of these three approaches has advocates from the image and model theory. Art historian Horst Bredenkamp considers models as elements of a higher ranked image act, which at the same time ascribes an "own image-active contribution" in order to draw attention to their visual presence (Bredekamp 2010: 292; comp. also 2010: 288). For Herbert Stachowiak (who developed his model typology significantly in the context of a picture theory), on the contrary, "graphic models" assume a prominent position and he further subdivides them into photographic, image, and representational models (1973: 159-174). His model character of images anticipates a perspective that is becoming increasingly important in the model theory proposed within the philosophy of science.

Ronald Giere and Nancy Nersessian independently discuss "visual models" (Giere 1996; Nersessian 2002) and Margaret Morrisson and Mary Morgan (1999: 33) as well as Mieke Boon and Tarja Knuuttila (2009: 701) refer to "diagrammatic models" - this is, however, an incomplete list. When, on the other hand, philosopher of science Rom Harré (1999) speaks of visual representations and models as the two primary instruments of "iconic thinking" and Max Black classifies the scale 
model as icon (1962: 221, referring to Peirce), there is the attempt to conceive modeling through a higher ranked symbol character. Since both models and images are often described as representations, it is tempting to emphasize their commonalities, as John Kulviki in Images (2014: 133ff.) (in the case of philosophy of images) and Bas van Fraassen in Scientific Representation. Paradoxes of Perspective (2008) (in the case of philosophy of science) do.

So that these paths do not go astray, one must avoid a strong broadening between the concepts of image and model, given that there is a great danger to lose necessary distinction through this conceptual conflation. ${ }^{25}$ Precisely, the case studies in this volume reveal that it should not be about the primacy of model or image, or about their leveling. Rather, they show that the dynamic interplay between forms of image and model seems to be of central importance in order to understand the changes brought about by computer-based modeling in design.

On the epistemic operativity of artifacts and their forms of manifestation. New light is shed on this matter when the relationship between image and model is examined from an operative perspective. Without hesitation, nowadays designing is described as a modeling process. This equation may be true as a rough approximation. Wherever a design is developed with efficient software and the corresponding hardware, this happens within the context of computer-aided models. Problems and possible solutions begin with blurred initial conditions that increasingly take shape. Step by step, facets of the design are explored, general conditions are tapped, connections are tested, scenarios are tried, consequences are played out, and potential partial results are repeatedly questioned. After endless iterative loops working through the project, the design is finally stabilized with a high degree of detail. Until that happens, the design has been tested and tried in many ways, that which proved to be wrong or unsound for further development was discarded, and what stood the tests was provisionally adopted. In this way, the computer model opens up processes of learning and understanding that turn it to an epistemic tool with particular forms of reasoning. When the processes are successfully brought to an end, a well-funded and specific knowledge about the designed has emerged, which allows converting the design into a 'real' artifact.

But under an operative perspective, these apparently model-like forms of reasoning turn out to be image-based procedures, because the actual use is marked by visual phenomena. The development of the model takes places on the screen, whose outlook works with the classical projection techniques of one or two planes, axonometry and perspective, while numerical and verbal notations play only a secondary role. Consequently, the reflection is visually-guided and the underlying

${ }^{25}$ Comp. the extension of the concept against the background of positions in art theory in Reinhard Wendler (2013: 168-177). 
conclusions are predominantly image-based. In this generative operativity, forms of imagery embody actual knowledge tools. Their great variety allows for different epistemic priorities during the handling, which can be selectively used for specific problems. At the same time, image forms provide essential means to obtain descriptions of the state of the model development. Plans or renderings, for example, which are derived and printed intermittently as manifestations of the model, fixate (partial) results. They can be included in further revision processes, but they can also serve as basis for communication or diffusion processes through their instrumental operativity. In this way, plans in the final phase of the design process contain the produced knowledge as manifestations of knowledge and become direct instructions for the construction. Under the heading forms of manifestation, however, it emerges another kind, this time in a new guise: the scale model. In particular, through the technology of rapid prototyping, the scale model can be created in an uncomplicated manner as a physical and haptic derivation of the computer model. But precisely these printouts make explicit the loss of significance of modeling at the operative level: the scale model is then the derivative of the computer model; as a design artifact, it has lost much of its explorative character. The model of the model can represent and test certain aspects of the design as a temporary excerpt. But its genesis is no longer based on the modeling process, but on the image-based reflection process discussed above. Here one can see the contrast with 'pre-digital' techniques in complete distinctiveness. In the use of traditional design tools there was a typical and clear dichotomy: on the one side was the graphic work with pen and paper as forms of imagery; on the other, the creation of material and tangible compounds of wood, cardboard or foam as forms of modeling. In the times of computer-based modeling, on the contrary, forms of imagery determine the domain of modeling and they become the dominant working interfaces and thus the primary reflection tools.

Whether images should be understood as models or models as images is a question that now appears to be inadequately posed at the operational level. The similarities between design images and design models are based on their epistemic potential, which can be deployed in their use. Because of this they can become powerful knowledge tools in the design process. The differences lie, however, in their specific strengths and weaknesses when referencing and reflecting. Depending on their conditions, each form and technique opens up very different thinking spaces. This makes it possible to systematically pursue epistemic interests, and depending on the problem, the appropriate tools can be selected. The graphic exploration with a coarse $6 \mathrm{~B}$ pencil on paper allows for quick and varied preliminary ideas that consciously make use of blurriness; the same medium would be unsuitable for accurate and detailed elaboration. Predetermined for the latter are instead the exact construction processes in the $2 \mathrm{D}$ and $2 \frac{1}{2}$ range on the screen. In contrast, questions regarding the 
spatial effect can be answered through small-scale models in 3D printing; but the same medium is useless to work out aspects of materiality and structural behavior. In turn, to investigate the complex structural system of a particular design variation, one should resort to an FEM modeler. In this way, the knowledge about the strengths and weaknesses of these reflection tools can be methodically used; the conditions of the medium are directly included in the development and can usefully be brought to bear.

This shows, then, that the diversity of operative artifacts is all but accidental. Their respective limitation in epistemic potential makes this abundance a necessary part of the design exploration. Cleverly combined, the different processes complement each other in order to develop and test the design in the most comprehensive way. The different forms of images and models can be specifically used to generate insights based on their core areas. Even more important is that results are obtained through divergent working processes which not only complement but mutually correct each other. Each tool allows examining issues from a different perspective. By overlapping the results, a balance with one another occurs. This is crucial for securing findings: due to the lack of direct verification of the obtained findings with reality, their reliability depends mainly on the quality of the processes undertaken by the operative artifacts. Through this, the seemingly categorical differences between forms of imagery and modeling dissolve. Rather, the specific epistemic characteristic and the capacity of a particular technique come to the fore, regardless of their belonging to the domain of the imagery or of modeling. Computer modeling, in turn, becomes a comprehensive umbrella term which is dominated at the operative level of imagery phenomena.

The success of imagery. One of the aims of this book is to better understand the role of imagery in the design process. As the case studies show, with the introduction of computer-based tools the relationship between imagery and modeling has changed, but in a different way from that which might have been expected. Rather than a marginalization of drawing and visual practices, their relevance increases even more through modeling. At the operative level, forms of imagery are the primary reflection tool in architecture, engineering and design. Once again, image-based practices prove to be particularly suited to create new artifacts. When anticipating the non-existent and thinking ahead on the future, forms of imagery exhibit a high epistemic capacity, be it in the form of concept development and genesis of forms, in planning variations and their selection processes, or in the communication and the diffusion of the results. Visual artifacts serve as a source of inspiration and as a design tool, as means of structuring and test environment, as deposits of knowledge as well as mediating instruments. It is not exaggerated to say that in the digital turn visual techniques assume the key position with respect to computer modeling. The extensive use of 
modeling techniques in design and construction leads in no way to a decline in the significance of imagery: today, the design process depends more than ever on image-based procedures. ${ }^{26}$

\section{References}

Alberti, L.B. (1755). The Architecture of Leon Batista Alberti in Ten Books, printed by Edward Owen. London. http://archimedes.mpiwg-

berlin.mpg.de/docuserver/images/archimedes/alber archi_003 en_1785/downloads/alber_archi 00 3 en_1785.text.pdf. Accessed 10 Jun 2015.

Ammon, S. (2015). Einige Überlegungen zur generativen und instrumentellen Operativität von technischen Bildern. In H. Depner (Ed.), Visuelle Philosophie (pp. 167-181). Würzburg:

Königshausen \& Neumann.

Baynes, K., \& Pugh, F. (1981). The art of the engineer. Guildford: Lutterworth Press.

Beyer, A., \& Lohoff, M. (Eds. 2005). Bild und Erkenntnis: Formen und Funktionen des Bildes in Wissenschaft und Technik. München/Berlin: Deutscher Kunstverlag.

Black, M. (1962). Models and archetypes [1958]. In idem, Models and metaphors: Studies in language and philosophy (pp. 219-243). Ithaca, NY: Cornell Univ. Press.

Blau, E., \& Kaufman, E. (Eds. 1989). Architecture and its image: Four centuries of architectural representation: Works from the collection of the Canadian Centre for Architecture. Montreal:

Centre Canadien d'Architecture/Canadian Centre for Architecture.

Booker, P. J. (1963). A history of engineering drawing. London: Chatto \& Windus.

Boon, M., \& Knuuttila, T. (2009). Models as epistemic tools in engineering sciences. In A. Meijers (Ed.), Philosophy of technology and engineering sciences, Handbook of the philosophy of science, Vol. 9 (pp. 693-726). Amsterdam: Elsevier.

Boumans, M. (1999). Built-in justification. In: Morgan, M. S., Morrison, M. (Eds.), Models as mediators: Perspectives on natural and social science (pp. 66-96). Cambridge: Cambridge Univ. Press.

Bräuer, S. (2015). Modelle von Bauwerken und baulichen/technischen Anlagen.

http://www.universitaetssammlungen.de/dokumentation/vertiefendes/modelle/bauwerke. Accessed 28 Aug 2015.

Bredekamp, H. (2010). Theorie des Bildakts: Frankfurter Adorno-Vorlesungen 2007. Frankfurt a. M.: Suhrkamp.

\footnotetext{
${ }^{26}$ This research received support from the European Union (Marie Skłodowska-Curie Fellowship, Grant Agreement No. 600209, Project IPODI).
} 
Bredekamp, H., Dünkel, V., Schneider, B. (Eds. 2015). The technical image: A history of styles in scientific imagery. Chicago: University of Chicago Press.

Carpo, M. (2001). Architecture in the age of printing: Orality, writing, typography, and printed images in the history of architectural theory. Cambridge, MA: MIT Press.

Carpo, M. (2011). The alphabet and the algorithm. Cambridge, MA: MIT Press.

Carpo, M. (Ed. 2013). The digital turn in architecture 1992-2012, AD Reader. Chichester: WileyBlackwell.

Carpo, M., \& Lemerle, F. (Eds. 2008). Perspective, projections, and design: Technologies of architectural representation. London/New York: Routledge.

Duden (2005). Modell. In Das Fremdwörterbuch, 8.th edition (p. 669). Mannheim: Dudenverlag. Elkins, J. (2003). Visual studies: A skeptical introduction. New York/London: Cornell Univ. Press. Elser, O., \& Cachola Schmal, P. (Eds. 2012). Das Architekturmodell: Werkzeug, Fetisch, kleine Utopie/The architectural model. Tool, fetish, small utopia, Ausstellungskatalog DAM Deutsches Architekturmuseum, Dezernat für Kultur und Wissenschaft, Stadt Frankfurt a. M. 2012. Zurich: Scheidegger \& Spiess.

Evans, R. (1995). The projective cast: Architecture and its three geometries. Cambridge, MA: MIT Press.

Evans, R. (1997). Translations from drawing to building [1986]. In idem, Translations from drawing to building and other essays (pp. 152-193). London: Architectural Association. Ewenstein, B., \& Whyte, J. (2009). Knowledge practices in design: The Role of visual representations as 'epistemic objects'. Organization Studies, 30(1), 7-30.

Ferguson, E. S. (1992). Engineering and the mind's eye. Cambridge, MA: MIT Press. Ford, B. J. (1993). Images of science: A history of scientific illustration. New York: Oxford University Press.

Fox Keller, E. (2000). Models of and models for: Theory and practice in contemporary biology. Philosophy of Science, 67, 72-86.

Frascari, M., Hale, J., Starkey, B. (Eds. 2007). From models to drawings: Imagination and representation in architecture. London/New York: Routledge.

Frigg, R. \& Hartmann, S. (2012). Models in Science. In E. N. Zalta (Ed.), The Stanford Encyclopedia of Philosophy. http://plato.stanford.edu/archives/fall2012/entries/models-science. Accessed 17 Apr 2015.

Froschauer, E. M. (2011). Architekturzeitschrift: Enzyklopädisches, spezielles, selektives und manifestierendes Wissen, oder: Architektur als vermittelte Mitteilung. In W. Sonne (Ed.), Die Medien der Architektur (pp. 275-301). München/Berlin: Deutscher Kunstverlag. 
Gänshirt, C. (2007): Werkzeuge für Ideen: Einführung ins architektonische Entwerfen.

Basel/Boston/Berlin: Birkhäuser.

Geyer, P. (2013). Von der digitalen Linie zum Systemmodell: Information und Wissen in der Entwurfsmodellierung mit dem Computer. In S. Ammon, E. M. Froschauer (Eds.), Wissenschaft

Entwerfen: Vom forschenden Entwerfen zur Entwurfsforschung der Architektur (pp. 231-265).

Munich: Fink.

Giere, R. N. (1996). Visual models and scientific judgment. In B. S. Baigrie (Ed.), Picturing

Knowledge: Historical and philosophical problems concerning the use of art in science (pp. 269302). Toronto: University of Toronto Press.

Gleiter, J.H., Korrek, N., Zimmermann, G. (Eds. 2008), Die Realität des Imaginären: Architektur und das digitale Bild, 10. Internationales Bauhaus-Kolloquium Weimar 2007. Weimar: Verlag der Bauhausuniversität Weimar.

Goldschmidt, G. (1994). On visual design thinking: The vis kids of architecture. Design Studies, $15(2), 158-174$.

Goodman, N. (1968). Languages of Art: An Approach to a Theory of Symbols. Indianapolis: BobbsMerrill.

Hambly, M. (1988). Drawing instruments 1580-1980. London: Sotheby's Publications.

Harré, R. (1999). Models and type-hierarchies: Cognitive foundations of iconic thinking. In R. Paton, \& I. Neilson (Eds.), Visual representations and interpretations (pp. 97-111). London:

Springer.

Hauschild, M, \& Karzel, R. (2010). Digitale Prozesse. Planung, Gestaltung, Fertigung. München: Institut für Internationale Architektur-Dokumentation.

Helmberger, W., Kockel V. (Eds. 1993). Rom über die Alpen tragen. Fürsten sammeln antike Architektur: Die Aschaffenburger Korkmodelle. Landshut/Ergolding: Arcos.

Henderson, K. (1999). On line and on paper: Visual representations, visual culture, and computer graphics in design engineering. Cambridge, MA: MIT Press.

Hentschel, K. (2014). Visual cultures in science and technology: A comparative history. Oxford: Oxford Univ. Press.

Hight, C. (2012). Manners of working: Fabricating representation in digital based design. In C. G. Crysler, S. Cairns, H. Heynen (Eds.), The SAGE Handbook of architectural theory (pp. 410-429). Los Angeles: Sage.

Hubig, C. (2010). Leistung und Grenzen der Virtualität beim Wissenserwerb. In K. Kornwachs (Ed.), Technologisches Wissen: Entstehung, Methoden, Strukturen (pp. 211-225).

Berlin/Heidelberg: Springer. 
Krämer, S. (2009). Operative Bildlichkeit: Von der ,Grammatologie‘ zu einer ,Diagrammatologie‘? Reflexionen über erkennendes, Sehen‘. In M. Heßler, \& D. Mersch (Eds.), Logik des Bildlichen: Zur Kritik der ikonischen Vernunft (pp. 94-122). Bielefeld: transcript.

Kulvicki, J. V. (2014). Images. London: Routledge.

Langer, B. (2011). Computerdarstellung: Vom Programm zum digitalen Ökosystem. In W. Sonne (Ed.), Die Medien der Architektur (pp. 157-168). München/Berlin: Deutscher Kunstverlag. Magnani, L., \& Nersessian, N. J. (Eds. 2002). Model-based reasoning: Science, technology, values. New York: Kluwer.

Magnani, L., Nersessian, N. J., Thagard, P. (Eds. 1999). Model-based reasoning in scientific discovery. New York: Kluwer.

Mahr, B. (2008). Ein Modell des Modellseins: Ein Beitrag zur Aufklärung des Modellbegriffs. In U. Dirks, \& E. Knobloch (Eds.), Modelle (pp. 187-218). Frankfurt a. M.: Lang.

Maynard, P. (2005). Drawing distinctions: The varieties of graphic expression. Ithaca, NY/London: Cornell Univ. Press.

Morgan, M. S. (1999). Learning from models. In: idem, Morrison, M. (Eds), Models as mediators: Perspectives on natural and social science (pp. 347-388). Cambridge: Cambridge Univ. Press. Morris, M. (2006). Model: Architecture and the miniature. Chichester: Wiley-Academy. Morrison, M., \& Morgan, M. S. (1999). Models as mediating instruments. In idem (Eds.), Models as mediators: Perspectives on natural and social science (pp. 10-37). Cambridge: Cambridge Univ. Press.

Müller, R. (1983). Zur Geschichte des Modelldenkens und des Modellbegriffs. In H. Stachowiak (Ed.), Modelle: Konstruktion der Wirklichkeit (pp. 17-86). Munich: Fink.

Müller, R. (2009). The notion of a model: A historical overview. In A. Meijers (Ed.), Philosophy of technology and engineering sciences, Handbook of the philosophy of science, Vol. 9 (pp. 637-664). Amsterdam: Elsevier.

Münster, S., Jahn P. H., Wacker, M. (2016). Von Plan- und Bildquellen zum virtuellen Gebäudemodell: Zur Bedeutung der Bildlichkeit für die digitale 3D-Rekonstruktion historischer Architektur. In S. Ammon, I. Hinterwaldner (Eds.), Bildlichkeit im Zeitalter der Modellierung. Operative Artefakte in Entwurfsprozessen der Architektur, des Designs und Ingenieurwesens (in print). Munich: Fink.

Nerdinger, W. (Ed. 1986). Die Architekturzeichnung: Vom barocken Idealplan zur Axonometrie: Zeichnungen aus der Architektursammlung der Technischen Universität München. Munich: Prestel. 
Nersessian, N. J. (2002). The cognitive basis of model-based reasoning in science. In P. Carruthers, S. Stich, M. Siegal (Eds.), The cognitive basis of science (pp. 133-153). Cambridge: Cambridge University Press.

Nersessian, N. J., \& Patton, C. (2009). Model-based reasoning in interdisciplinary engineering. In A. Meijers (Ed.), Philosophy of technology and engineering sciences, Handbook of the philosophy of science, Vol. 9 (pp. 727-757). Amsterdam: Elsevier.

Peddie, J. (2013). The history of visual magic in computers: How beautiful images are made in $C A D, 3 D, V R$ and $A R$. London: Springer.

Pérez-Gómez, A., \& Pelletier, L. (1997). Architectural representation and the perspective hinge. Cambridge, MA/London: MIT Press.

Picon, A. (1992). French architects and engineers in the age of enlightenment. Cambridge: Cambridge University Press.

Johannes, R. (Ed. 2009). Entwerfen. Architektenausbildung in Europa von Vitruv bis Mitte des 20. Jahrhunderts: Geschichte - Theorie - Praxis. Hamburg: Junius.

Reuther, H. \& Berckenhagen, E. (1994). Deutsche Architekturmodelle. Projekthilfe zwischen 1500 und 1900. Berlin: Deutscher Verlag für Kunstwissenschaft.

Robin, H. (1992). The scientific image: From cave to computer. New York: Harry N. Abrams. Sachs-Hombach, K. (Ed. 2005). Bildwissenschaft: Disziplinen, Themen, Methoden. Frankfurt a. M.: Suhrkamp.

Sachsse, R. (2011). Architekturfotografie: Das analoge Bild der klassischen Moderne - zur gegenseitigen Historisierung von Fotografie und Architektur im 19. und 20. Jahrhundert. In: W. Sonne (Ed.), Die Medien der Architektur (pp. 85-97). München/Berlin: Deutscher Kunstverlag. Schaffer, S. (2004). Fish and ships: Models in the age of reason. In S. De Chadarevian, \& N. Hopwood (Eds.), Models. The third dimension of science (pp. 71-105). Standford: Standford University Press 2004.

Scholz, O. R. (2009). Abbilder und Entwürfe: Bilder und die Strukturen der menschlichen Intentionalität. In K. Sachs-Hombach (Ed.), Bildtheorien: Anthropologische und kulturelle Grundlagen des Visualistic Turn (pp. 146-162). Frankfurt a. M.: Suhrkamp.

Scholz, O. R. (2012). Bilder in Wissenschaften, Design und Technik: Grundlegende Formen und Funktionen. In D. Liebsch \& N. Mößner (Eds.), Visualisierung und Erkenntnis: Bildverstehen und Bildverwenden in Natur- und Geisteswissenschaften (pp. 43-57). Köln: Herbert von Halem Verlag. Schön, D. A. (1983). The reflective practitioner: How professionals think in action. New York: Basic Books. 
Smith, A. C. (2004). Architectural model as machine: A new view of models from antiquity to the present day. Oxford: Architectural Press.

Spiller, N. (2008). Digital architecture now: A global survey of emerging talent. London: Thames \& Hudson.

Spiro, A., \& Ganzoni, D. (Eds. 2013). Der Bauplan: Werkzeug des Architekten. Zurich: Park Books.

Stachowiak, H. (1973). Allgemeine Modelltheorie. Wien/New York: Springer.

Tversky, B. (2005). Visuospatial reasoning. In K. J. Holyoak, \& R. G. Morrison (Eds.), The

Cambridge handbook of thinking and reasoning (pp. 209-240). Cambridge: Cambridge University Press.

van Fraassen, B. C. (2008). Scientific representation: Paradoxes of perspective. Oxford: Clarendon Press.

Weisberg, M. (2013). Simulation and similarity: Using models to understand the world.

Oxford/New York/Auckland: Oxford University Press.

Wendler, R. (2013). Das Model zwischen Kunst und Wissenschaft. Munich: Fink.

Winfried Nerdinger (Ed. 2012). Der Architekt: Geschichte und Gegenwart eines Berufsstandes, Ausstellungskatalog Architekturmuseum der TU München in der Pinakothek der Moderne, München 2013, Vol. 1 and 2. Munich: Prestel.

Yaneva, A. (2009). The making of a building: A pragmatist approach to architecture. Bern: Peter Lang.

Zauzig, O. (2015). Modelle von Maschinen, Fahrzeugen, Geräten und Instrumenten.

http://www.universitaetssammlungen.de/dokumentation/vertiefendes/modelle/maschinen. Accessed 28 Aug 2015.

Zwart, S. D. (2009). Scale modeling in engineering: Froude's case. In A. Meijers (Ed.), Philosophy of technology and engineering sciences, Handbook of the philosophy of science, Vol. 9 (pp. 759798). Amsterdam: Elsevier. 